\title{
NUMERICAL AND EXPERIMENTAL INVESTIGATIONS ON PATTERNED FLOW DISTRIBUTION THROUGH MANIFOLDS IN ELECTRONICS COOLING
}

\author{
ANNAPURNA SOGUNURU ${ }^{1}$, YASH KRISHNA MENON ${ }^{2}$, Dr. A. C. NIRANJANAPPA ${ }^{3} \&$ \\ Dr. K. HEMACHANDRA REDDY ${ }^{4}$ \\ ${ }^{1}$ ResearchScholar, JNTU College of Engineering Anantapuramu, India \\ ${ }^{2}$ Junior Research Fellow, Centre for Airborne Systems, DRDO, India \\ ${ }^{3}$ Scientist, Centre for Airborne Systems, DRDO, India \\ ${ }^{4}$ Professor, Mechanical Engineering, JNTU College of Engineering Anantapuramu, India
}

\begin{abstract}
In large electronic systems where the thermal loads are distributed in a pattern, coolant flow requirements also need to follow similar pattern. Available literature mainly focuses on uniform flow distribution through manifolds. However, for rack mounted electronics where heat loads are in a repetitive pattern, flow distribution also follows similar pattern. This paper presents a methodical approach in providing the pattern flow distribution through manifold system. Based on principle of pressure driving the flow, the desired flow is achieved by introduction of required pressure drop by means of suitable orifices. Three types of patterned flows are presented in this paper. The average percentage deviations between the required flow, CFD and experimental results are compared and found to be in close agreement with each other. Based on the results, it is observed that the proposed methodology provides an effective and simplified solution that can be adopted in electronics cooling in case of dissimilar heat load characteristics with repeated patterns.

KEYWORDS: Electronics Cooling, Manifolds, Uniform Flow \& Patterned Flow
\end{abstract}

Received: Feb 08, 2020; Accepted: Feb 28, 2020; Published: Apr 02, 2020; Paper Id.: IJMPERDAPR20295

\section{NOMENCLATURE}

a: Cross sectional area of orifice, $\mathrm{m}^{2}$

A: Cross sectional area of branch channel, $\mathrm{m}^{2}$

$\mathrm{C}_{\mathrm{d}}$ : Orifice coefficient of discharge

$\mathrm{C}_{\mathrm{p}}$ : Specific heat, $\mathrm{kJ} / \mathrm{KgK}$

$\mathrm{d}$ : Orifice diameter, $\mathrm{m}$

D: Branch channel diameter, $m$

H: Heat load, W

m : Mass flow rate, $\mathrm{kg} / \mathrm{s}$

Q: Water flow rate, $\mathrm{m}^{3} / \mathrm{s}$

$V:$ Volume flow rate, $\mathrm{m}^{3} / \mathrm{s}$

$\rho:$ Density, $\mathrm{kg} / \mathrm{m}^{3}$ 
$\Delta \mathrm{p}:$ Pressure drop across orifice, $\mathrm{Pa}$

$\Delta \mathrm{t}$ : Temperature gradient, ${ }^{0} \mathrm{C}$

\section{INTRODUCTION}

Electronic devices are penetrating all walks of life and their performance requirements are ever increasing to make them more powerful, miniaturised and reliable. Since the hot spot temperatures affect component reliability, thermal management of these devices by way of maintaining them below the limiting temperature is an important design focus. Different cooling methods are adopted to reduce hot spot temperatures by means of conduction, convection and radiation or any combination of these methods. Cooling methods employed in electronics cooling can be air or liquid cooling, direct or indirect cooling, single or phase-change type [1]. When the thermal loads are high, liquid cooling is resorted to. One of the variants of these cooling methods is indirect single-phase liquid cooling. In this, the liquid coolant circulates through the heat sink and carries away the heat. When numbers of electronics are more, coolant distribution is done through manifolds.

A manifold is a flow channel in which fluid enters and leaves through the pores of the channel. When the fluid branches out through the pores laterally, it is termed as distribution manifold. In this, the fluid stream is decelerated in the flow direction. When the fluid is added from branch points to the flow channel, in the flow direction, it is called collection manifold. In this, fluid accelerates in the flow direction. Main flow channel and branch points are also known as header and channels respectively. When both distribution and collection manifolds are connected and fluid direction is same in both, then it is called parallel or Z-configuration flow (Figure 1a). When the flow direction is opposite in the distribution and collection manifolds, it is called reverse or U-configuration flow (Figure1b).

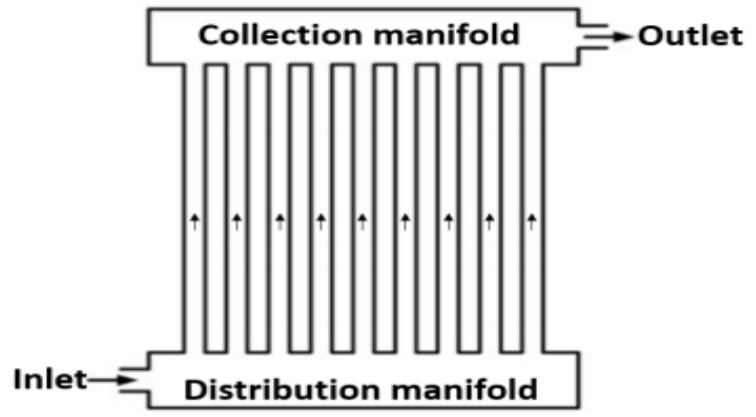

Figure 1a: Z-Type Manifold Configuration.

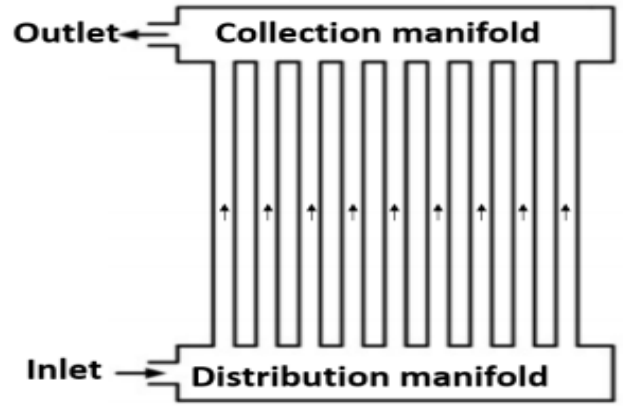

Figure 1b: U-Type Manifold Configuration.

The flow configuration inside the manifolds is complex in nature. It is a function of Reynolds number, ratio of sum of all channel area to header area, number of channels, pitch of channels and ratio of length to diameter of the manifolds.

Formulation of flow distribution inside the manifolds in the literature is based on two important assumptions: (i) flow uniformity and (ii) uniform pitch of the branch channels. Several discrete and analytical models framed by researchers are on these two assumptions. These assumptions reduce the complexity of the governing equations.

Flow distribution in manifolds was addressed by Acrivos in 1959 [2]. Dutta \& Majumdar, Bajura \& Jones, Bassiuony \& Martin [3-6] developed analytical models which were validated experimentally but for manifolds of short length by neglecting frictional effects. J. Wang [7-11] developed analytical models considering both momentum and 
friction factors along with the flow influencing factors in U-type and Z-type flow configurations.

Several other researchers considered geometrical modifications to achieve the flow uniformity in the channels. These methods include structural modification of headers. Studies using triangular, rectangular, trapezoidal headers showed that triangular headers are good in flow distribution compared to rectangular and trapezoidal headers [12]. Also, increasing or decreasing the area by tapering headers [13,14], introduction of baffle plates, changing the configurations of increasers in the headers[15] also increase flow uniformity.

However, geometrical modifications always might not be feasible in all applications in terms of space constraints, and manufacturing criticalities. A quasi-analytical method developed by Eprahim M. Sparrow is very simple, yet having potential application in achieving flow uniformity [16]. The research by Zhang et. al.[17] describes flow uniformity in the dividing manifold system with parallel pipe arrays(DMS-PPA) for the anti-parallel flow direction.

All the above studies reveal that performance of the manifold distribution has been quantified by the degree of flow uniformity it provides. However, there are situations where electronic units mounted in a rack as shown in Figure.2, are of similar dimensions, but have patterned heat load distributions. If the flow distributions are designed considering the highest heat load, it increases overall power, material and space requirements. In such a situation, instead of a uniform flow, a patterned flow distribution can provide an optimal solution. To the author's knowledge, very limited literature is available that addresses the desired or patterned flow distribution.

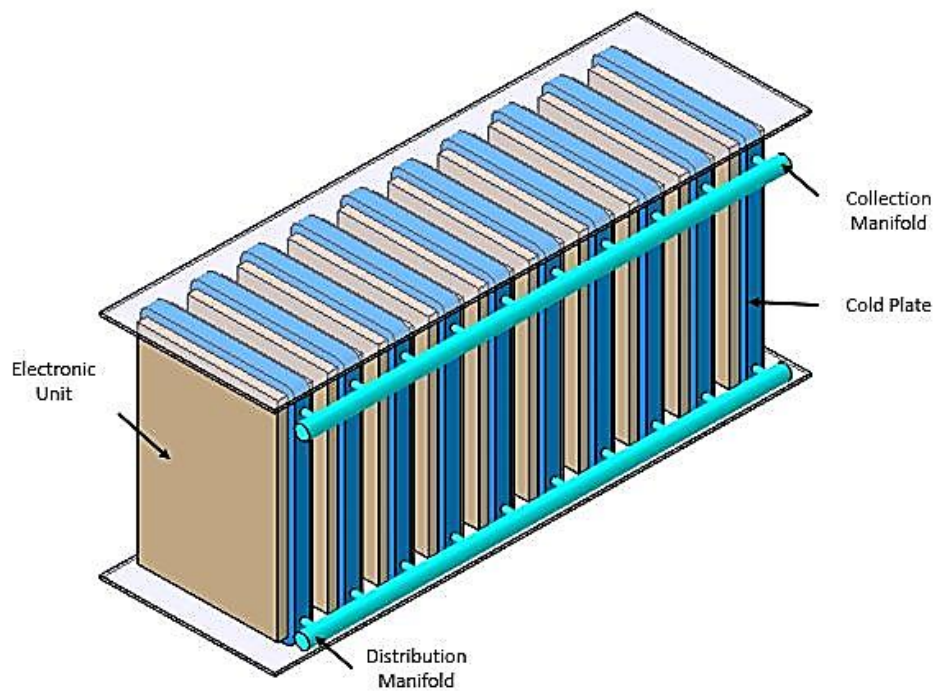

Figure 2: Electronics Mounted Inside the Rack.

Formulation of analytical equations and finding solutions to this kind of flow distribution is quite complex. Numerical simulations to study 3D flow phenomenon inside the manifolds can give more realistic approach. However, numerical simulations are specific to each configuration and arriving at a suitable flow requirement by a unified approach rather than trial and error approach is the requirement. This paper provides a methodology of arriving at pattern flow distribution using numerical simulations, followed by experimental validation. This methodology is explained by using the problem cases as mentioned in the subsequent section.

\section{PROBLEM DEFINITION}

Since the objective is to meet the flow requirements, to reduce the complexity of numerical modelling, each cold plate is 
modelled as a flow channel. Flow requirements to cool the electronics are calculated using the formula

$$
H=m C_{p} \Delta t
$$

Where, $\mathrm{Cp}$ is a constant at a particular temperature. For a defined temperature gradient, mass flow rate of the coolant is proportional to the heat load.

$\dot{m} \ltimes H$

mass flow rate can also be expressed as

$$
\dot{m}=\rho \dot{V}
$$

Hence,

$\sqrt{ } \propto \mathrm{H}$

Equation (4) shows that, the volume flow requirements are proportional to the heat load and form a set of repeated pattern for patterned heat loads. The calculated flow requirements are shown in Figure3a, Figure3b and Figure3c respectively. All these requirements are considered for the same configuration of overall manifold length and pitch of branch channels.

For each channel shown in $\mathrm{x}$-axis, volume flow rate is shown as litres per minute (lpm) on the $y$-axis. For all the cases, a total of $1 \mathrm{lpm}$ flow rate is considered. Water is considered as coolant. All the three configurations fall in the regime of laminar flow with Reynold's number $<2100$.

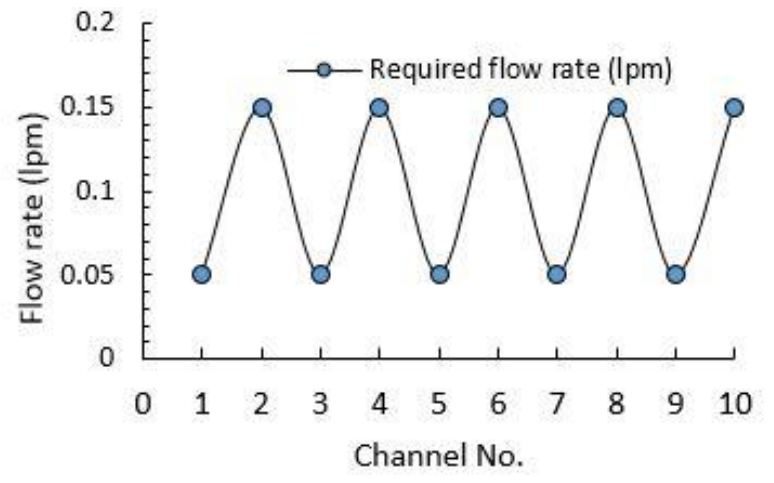

Figure 3a: Pattern-1.

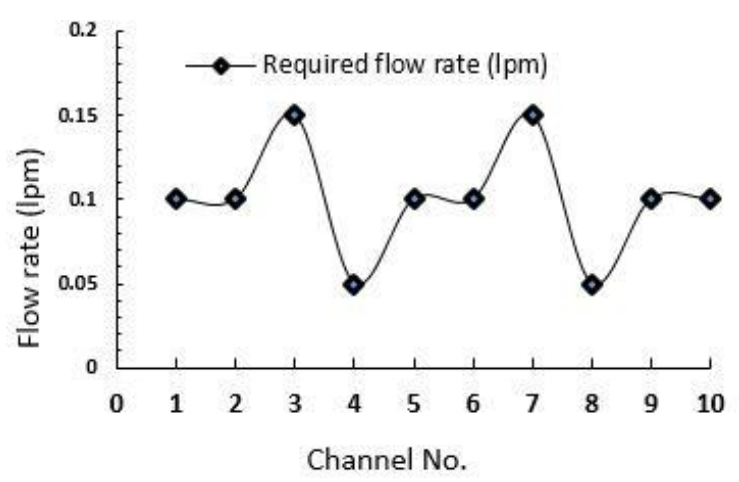

Figure 3b: Pattern-2.

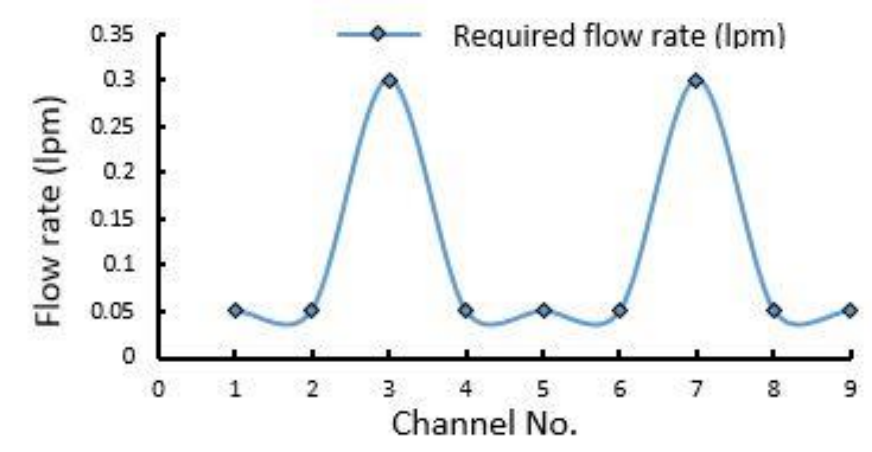

Figure 3c: Pattern-3. 


\section{METHODOLOGY}

The fluid flow pattern across each branch channel of the manifolds is governed by the pressure gradient/drop across that channel, inside the manifold system. Flow across channels is proportional to the pressure drop across the channels. Hence by introducing appropriate resistances in the form of orifices, inside the flow channels, the desired pattern flow can be attained. The sequence of proposed procedure is as follows:

Step-1. Pressure gradient across each branch channel for the given geometry without orifice is obtained by numerical simulations.

Step-2. The required pressure gradient across each branch channels that drives the desired flow is calculated using Hagen-Poiseuille equation[18] .

Step-3. For the pressure difference across branch channels obtained by step-1\& Step-2, the orifice diameters are found by solving the orifice equation using the MATLAB code.

Orifice equation:

$$
Q=\frac{C_{d} a \sqrt{2 \Delta p}}{\sqrt{\rho\left(1-\beta^{4}\right)}}
$$

Where $\beta=d / D$

Step-4. Numerical simulations are performed and flow deviation is measured with reference to the desired flow for each channel. Based on the percentage deviation from the desired flow across each branch channel, orifice diameters are determined for the next iteration.

If the obtained flow rate is less than the desired flow, orifice diameter is increased by the calculated percentage deviation and vice versa. The upper limit for increasing the orifice diameter is the diameter of channel itself i.e. maximum flow possible in a channel is without any orifice. Detailed procedure of arriving at the pattern flow distribution is described in the flow chart as shown in Figure 4.

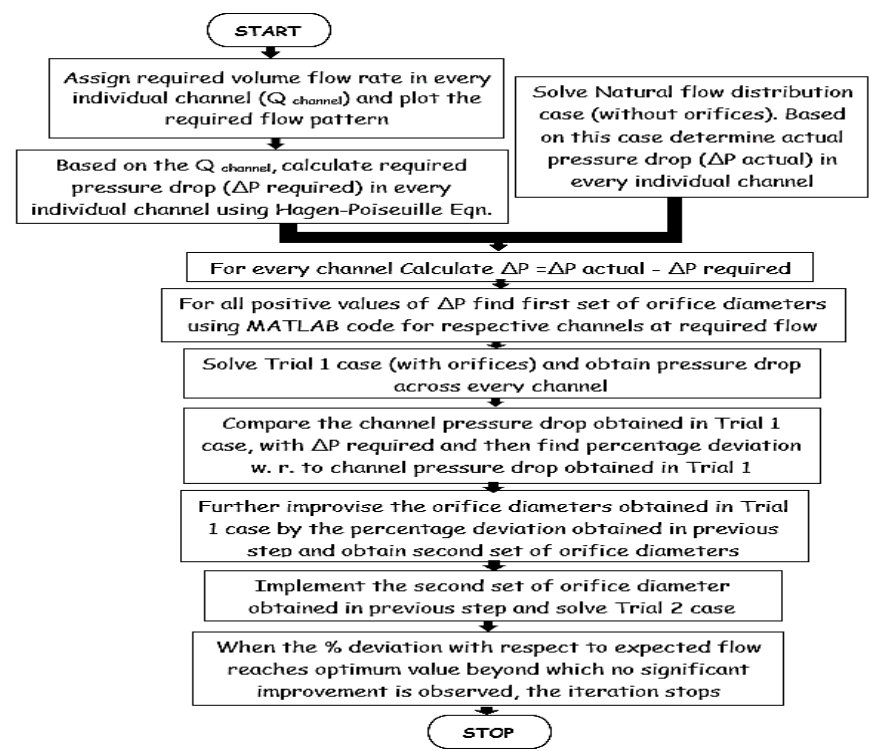

Figure 4: Methodology. 


\section{NUMERICAL INVESTIGATIONS}

Figure 5 shows the computational model used for CFD analysis. It consists of ten number of channels with a pitch of $70 \mathrm{~mm}$ for the flow pattern-1 and pattern-2. First 9 channels are considered for the flow pattern-3. Z-type manifold configuration is considered for the present study. Diameters of header and channel are taken as $12 \mathrm{~mm}$ and $6.5 \mathrm{~mm}$ respectively. Total length of the manifold considered is $700 \mathrm{~mm}$.

Water is considered as coolant. Density of water is taken as $998 \mathrm{~kg} / \mathrm{m}^{3}$ for the numerical simulations. Bottom inlet and top outlet are considered for the manifold system and 3Dnumerical simulations are carried out in ANSYS Fluent V17.0 CFD solver. Laminar flow with velocity inlet and pressure outlet boundary conditions are imposed. Using the automatic grid-generating tool ANSYS ICEM-CFD, hybrid grid is generated for the whole computational domain. Very fine grids are used in the some areas where the variation in the flow parameter is high, for accurate prediction of fluid properties, for example at the combining and dividing junctions of the manifolds with the branch channels, element sizing is made very fine $(0.002 \mathrm{~mm})$ to accurately capture the minor losses during turning of the fluid. Average element quality of the entire fluid domain is maintained at 0.7 for all the analysed cases. The analysis was performed using Steady state solver with incompressible flow. The fluid flow conditions in the domain are governed by the conservation laws of mass and momentum. These governing equations are solved using pressure-based solver. Second and higher order numerical schemes were used for discretization of governing equations. The SIMPLE algorithm is selected for pressure-velocity coupling. The convergence criterion is set in such a way that the residual of each calculated parameter is less than 10-5. All the simulations were carried out using parallel processing system having 32 core Intel® Xeon® processor. All the cases reached the converged solution within about 1500 iterations on a 64 GB RAM work station.

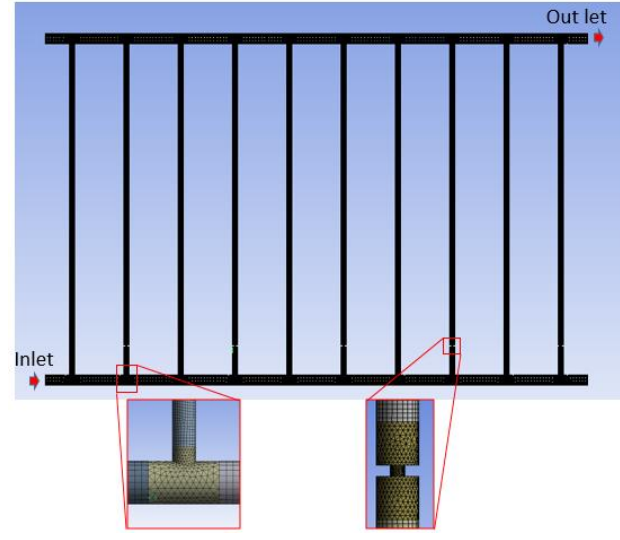

Figure 5: Computational Model.

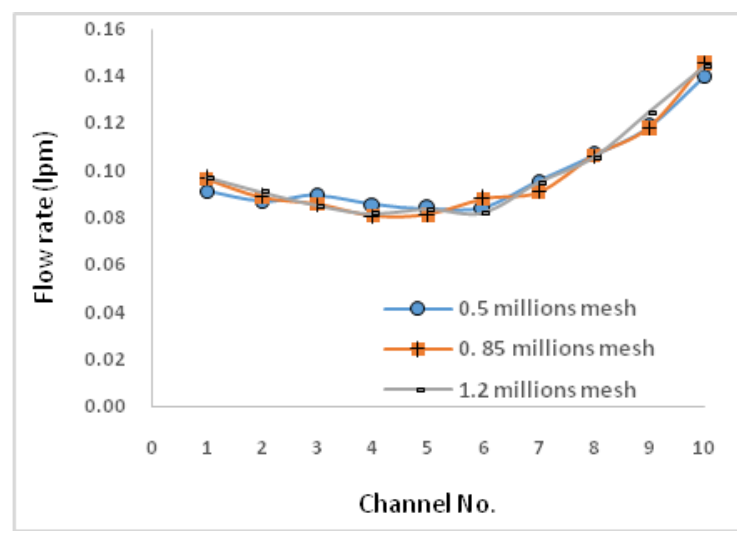

Figure 6: Grid Independence Study.

Grid independence study is carried out for the cases of natural flow configuration, that is the configuration with no orifices in the branch channels. Flow patterns are compared for 0.5, 0.85 and 1.24 million elements and variation in the flow and pressure drop parameters is found to be within 1-5\% as shown in Figure 6. Since this variation is small, all the cases are solved for the grid size between 0.8 to 1.3 million elements.

\section{NUMERICAL RESULTS AND DISCUSSION}

Flow rates across each branch channels for all three patterns obtained by numerical simulations are presented in the Figure 7a, Figure 7b and Figure7c. Average percentage deviation vs. the iteration number is plotted in Figure 8 and it is observed 
that no significant change is seen from second to third iteration for all the three patterns. Hence the iterations are not continued after the third one. Orifice diameters obtained from the simulations are presented in Table-1. It is to be noted that, where the orifice sizes are not specified, the pipe will be the straight channel without orifices.

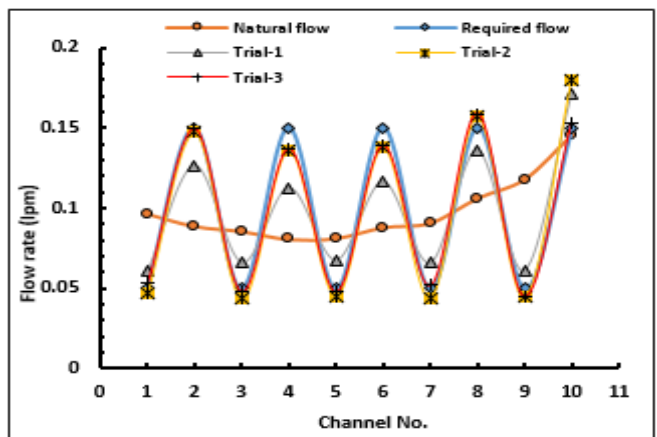

Figure 7a: Pattern-1.

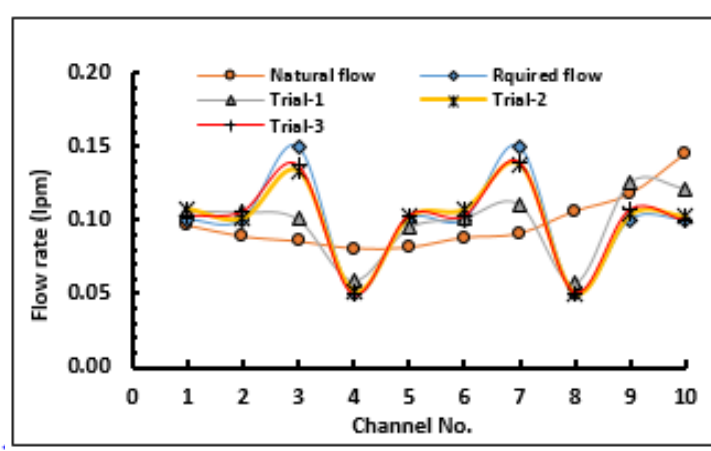

Figure 7b: Pattern-2.

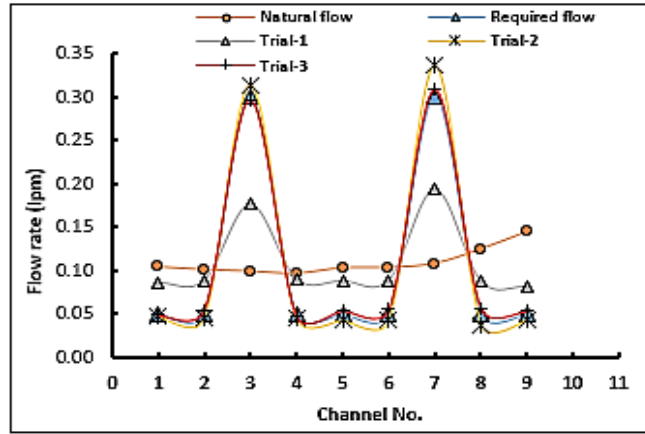

Figure 7c: Pattern-3.

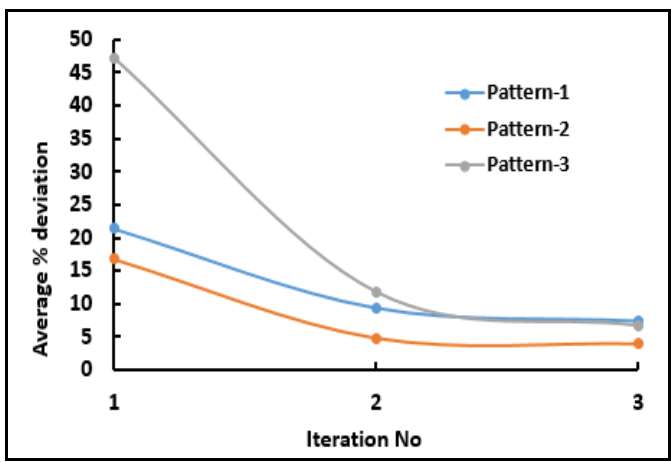

Figure 8: Average\% deviation from there quired flow vs. Iteration No.

Table 1: Orifice Diameters Obtained after Second Iteration

\begin{tabular}{|c|c|c|c|}
\hline Channel No. & Pattern-1 & Pattern-2 & Pattern-3 \\
\hline 1 & 2.4 & 4.5 & 1.6 \\
\hline 2 & - & 4.5 & 1.6 \\
\hline 3 & 2.3 & - & - \\
\hline 4 & - & 2.7 & 1.6 \\
\hline 5 & 2.3 & 4.5 & 1.6 \\
\hline 6 & - & 4.5 & 1.6 \\
\hline 7 & 2.2 & - & - \\
\hline 8 & - & 2.4 & 1.5 \\
\hline 9 & 2.1 & 3.8 & 1.5 \\
\hline 10 & 5.7 & 3.3 & - \\
\hline
\end{tabular}




\section{EXPERIMENTAL SET-UP}

To validate the analysis results, experimentation is carried out. Figure 9 shows experimental set-up. For a better understanding, detailed schematic layout that represents all the components of the experimental set up is shown in Figure10. Inner diameter of the rota meter is $6.5 \mathrm{~mm}$ which is also the inner diameter of the channel. Total length of the manifold is $700 \mathrm{~mm}$ and height of the channel is $440 \mathrm{~mm}$. Manifold tubes are of inner diameter $12 \mathrm{~mm}$. All the joints are connected with the leak proof quick dis-connect couplings. Each channel rotameter is graduated between 0-0.3 lpm with a least count of $0.011 \mathrm{pm}$. Accuracy of the rotameters is $\pm 0.25 \%$. At inlet side two rota-meters are connected. The first one has range of 0-5 lpm with least count of $0.2 \mathrm{lpm}$. The second one has range of 0-25lpm with least count of $0.5 \mathrm{lpm}$. A submersible water pump of 20lpm pumping capacity connected to $0.5 \mathrm{~kW}$ motor that runs on single phase power supply is connected to the water reservoir. Water reservoir size is $0.25 \mathrm{mx} 0.25 \mathrm{mx} 0.5 \mathrm{~m}$ with 30 litres capacity. Water level indicator is attached to this reservoir. The water delivery line that runs from the pump has a flow control valve that can be operated manually. Since the motor is of constant RPM, when the flow control valve is operated, water which is excess to the test requirements is made to return to the reservoir through a bypass pipe line.
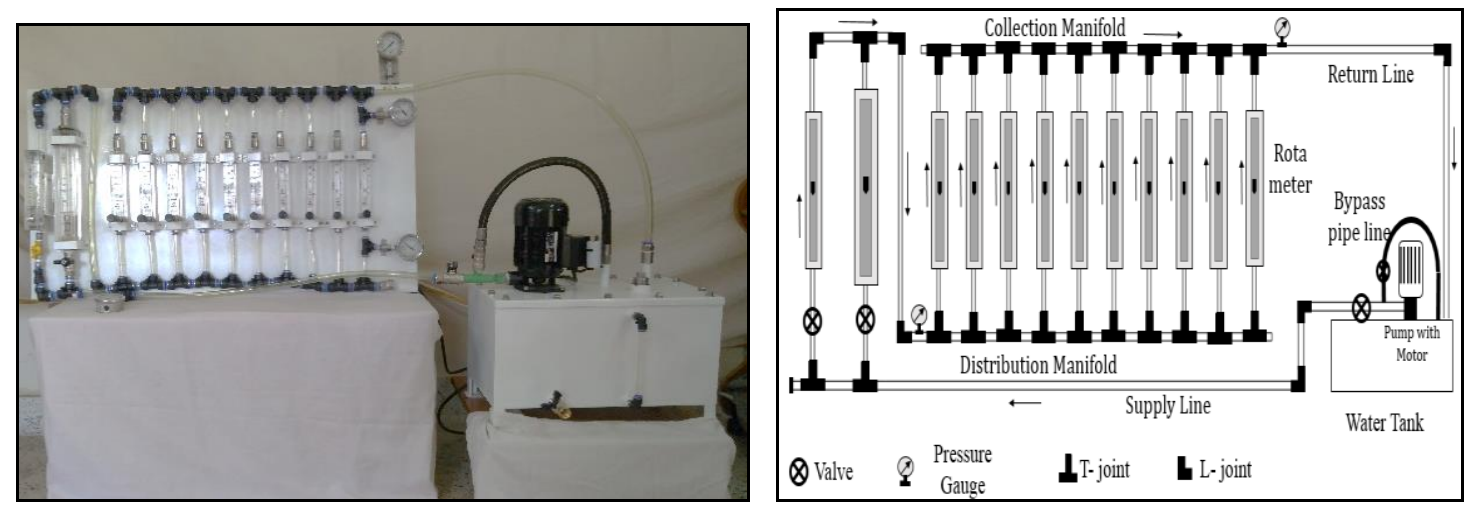

Figure 9: Experimental Set-up

Figure 10: Schematic Layout of the Experimental Set-up

Before experimentation, each rotameter is verified with known volume flow rate of water to find the correction factor. For each pattern flow configuration, experiments are conducted for 4 times to verify repeatability.

\section{RESULTS AND DISCUSSIONS}

Figure 11 provides a comparison of flow rate through branch channels between the results obtained from simulations and experiment. It is observed that there is an average deviation of $9.8 \%$ between the two.

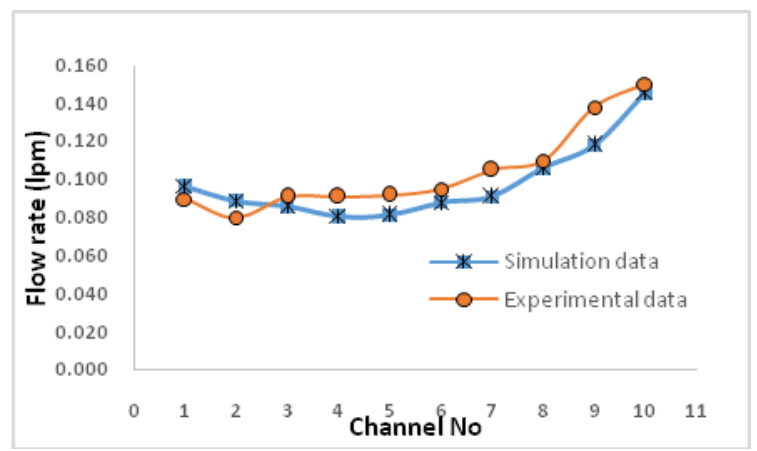

Figure 11: Results Comparison for Natural flow-Experimental \& Numerical 
Comparison between the required flow, results obtained from CFD simulations and experimental results are plotted in Figure 12a, Figure 12b and Figure 12c for pattern-1, pattern-2 and pattern-3 respectively.

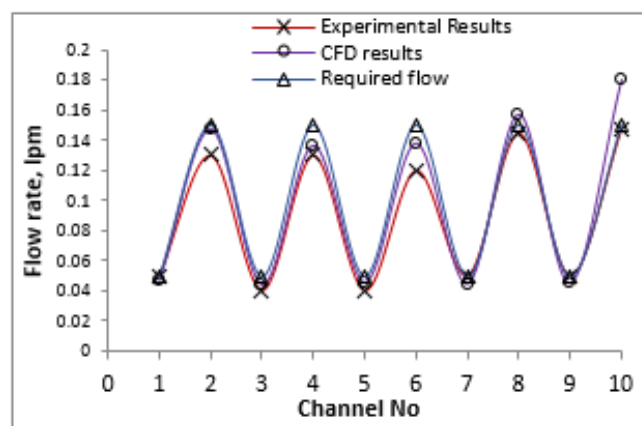

Figure 12a: Pattern-1

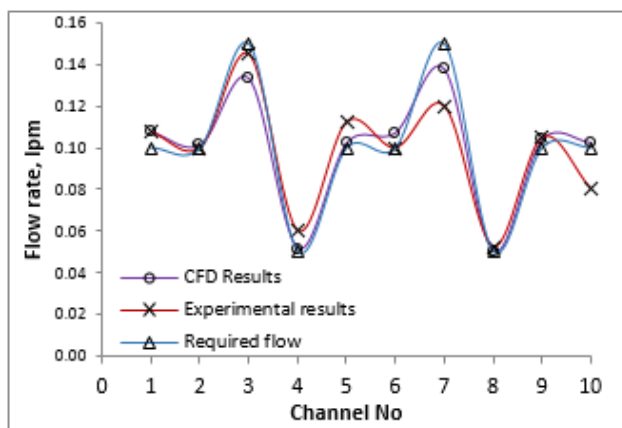

Figure 12b: Pattern-2

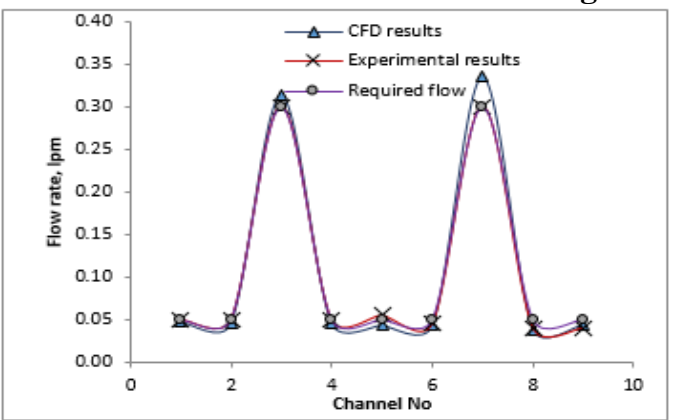

Figure: 12c Pattern-3

Average deviation from the flow requirements and the experimental results for pattern-1, pattern-2 and pattern-3 are found to be $4.5 \%, 3.9 \%$ and $6.7 \%$ respectively which are in close agreement to each other.

\section{CONCLUSIONS}

In the emerging new requirements of cooling of the electronic units, the uniform flow distribution may not always provide optimal solution. For the similar geometry configurations and equal spacing of the electronics inside the racks, three types of patterns are taken as case studies and solved with the proposed methodology. The methodology developed to arrive at desired pattern flows is demonstrated using numerical simulations and the same is validated by experimental results. The average percentage deviations between the required flow, CFD and experimental results are summarised and presented in Table-2. It is seen that all are in close agreement with each other.

Table 2: Average Percentage Deviations

\begin{tabular}{|c|c|c|c|}
\hline Pattern & $\begin{array}{c}\text { Required Flow } \\
\text { \& CFD Result }\end{array}$ & $\begin{array}{c}\text { Required Flow \& } \\
\text { Experimental } \\
\text { Result }\end{array}$ & $\begin{array}{c}\text { CFD \& Experimental } \\
\text { Result }\end{array}$ \\
\hline 1 & 4.5 & 9.16 & 11.4 \\
\hline 2 & 3.9 & 9.3 & 6.7 \\
\hline 3 & 6.7 & 4.4 & 9.3 \\
\hline
\end{tabular}

This methodology provides an effective and simplified solution that can be adopted in electronics cooling in case of dissimilar heat load characteristics with repeated patterns.

\section{ACKNOWLEDGEMENTS}

Authors would like to thank Sri. M. S. Easwaran, Director, CABS, Ms. Suma Varughese, OS and Mr. P. Vikram for their 
valuable inputs. Also, they would like to thank M/s Entec Engineering Company for making the test setup available for the experimental purpose.

\section{REFERENCES}

1. Suresh. V. Garimella, Amy S. Fleischer, Jayanthi Y. Murthy, Ali Keshavarzi, Ravi Prasher, Chandrakanth Patel, Sushil H. Bhavani, R. Venkatasubramanian, Ravi Mahajan, Y. Joshi, Bhagat Sammakia, Bruce A. Myers, Len Chorosinski, Martine Baelmans, Prabhu Sathyamurthy, Peter E. Raad (2008), Thermal challenges in NextGeneration Electronic Systems, IEEE Transactions on Components and packaging technologies, 31, No.4, pp. 801-815.

2. A. Acrivos, B. D. Babcock and R. L. Pigford(1959), Flow distribution in Manifolds, Chemical Engineering Science, 10, pp. 121-124.

3. B. Datta and A. K. Majumdar (1980), Flow Distribution in Parallel and Reverse Flow Manifolds, Int. J. Heat \& Fluid Flow, 2, No. 4, pp.253-262.

4. R. A. Bajura, E. H. Jones, JR.(1976), Flow Distribution Manifolds, ASME Gas Turbines and Fluids Engineering Conference,76, pp.654-665.

5. M. K. Bassiouny and H. Martin(1984a), Flow distribution and pressure drop in Plate heat exchangers-I U-type arrangement, Chemical Engineering Science,39, No.4, pp 693-700.

6. "Use of Internal Threads of Different Pitches to Enhance Heat Transfer in a Circular Channel", BEST: International Journal of Management, Information Technology and Engineering (BEST: IJMITE), Vol. 3, Issue 1, pp. $1-4$

7. M. K. Bassiouny and H. Martin(1984b), Flow Distribution and Pressure drop in Plate Heat Exchangers-II Z-Type arrangement, Chemical Engineering Science,39, No.4, pp. 701-704.

8. Junye Wang(2008), Pressure drop and flow distribution in parallel-channel configuration of fuel cells: U-type arrangement, Int. J. Hydrogen Energy,33, pp. 6339-6350.

9. Junye Wang(2010), Pressure drop and flow distribution in parallel-channel configuration of fuel cells: Z-type arrangement', Int. J. f Hydrogen Energy 35, pp. 5498-5509.

10. Junye Wang (2011), Theory of flow distribution in manifolds, Chemical Engineering J., 168(3), pp.1331-1345.

11. Junye Wang, Hualin Wang (2012), Discrete approach for flow field designs of parallel channel configurations in fuel cells, International journal of hydrogen energy, 37, pp. 10881-10897.

12. "Review of Laser Plastic Welding Process", IMPACT: International Journal of Research in Engineering \& Technology (IMPACT: IJRET), Vol. 2, Issue 2, pp. 191-206

13. Junye Wang, Hualin Wang(2015), Discrete method for design of flow distribution in manifolds, Applied Thermal Engineering, 89, pp.927-945.

14. Sooyoun Kim, Eunsoo Choi and Young I. Cho (1995), The effect of header shapes on the flow distribution in a manifold for electronic packaging applications, Int. Comm. in Heat and Mass Transfer, 22, No.3, pp 329-341. 
15. Osamu Tonomura, Shotaro Tanaka, Masaru Noda, Manabu Kano, Shinji Hasabe, Iori Hashimoto(2004), CFD based design of manifold in plate-fin micro devices, Chemical Engineering J.101(1-3), pp. 397-402.

16. Cyril Pistoresi, Yilin Fan, Lingai Luo.(2015), Numerical study on the improvement of flow distribution uniformity among parallel mini-channels, Chem. Engineering and Processing,95, pp.63-71.

17. "Comparative Evaluation of Untextured and Textured WC Inserts 3 Under Dry and Near Dry Machining of C45 Steel”, International Journal of General Engineering and Technology (IJGET), Vol. 6, Issue 5, pp. 1-16

18. Juliang Xie, Yong Shao, Yumei Xu, Jian Yang, Shuwen Zhang(2015), Structural Optimisations of U-and Z-Type Manifolds for Uniform Flow Distribution by Applying an Increaser and Baffle Plates, Chemical Engineering Technology,38(12), pp.2217-2225.

19. Eprahaim M. Sparraow, Jimmy C. K. Tong and John P. Abraham (2007), A Quasi-Analytical method for Fluid Flow in a Multi-Inlet Collection Manifold (2007), ASME J. Fluids Engineering, 129, pp:579-586.

20. "Recent Trends and Advancements in the field of Micro 481 Electrical and mechanical Systems (MEMS) Technology", IJMPERD, Vol. 7, Issue 6, pp. 479-488

21. Wanqing Zhang, Angui Li, Ran Gao, Cheng Li (2018), Effect of geometric structures on flow uniformity and pressure drop in dividing manifold systems with parallel pipe arrays, Int. J. Heat and Mass Transfer, 127, pp.870-881.

22. Yunus A Cengel, John M. Cimbala (2006), Fluid Mechanics, Fundamentals and Applications, Mc Graw Hill Higher Education.

\section{AUTHORS PROFILE}

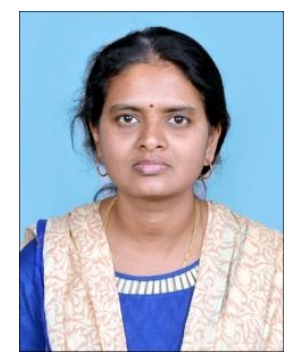

Ms. S. Annapurna, received her B.Tech. (Mechanical Engineering) in 1995 and M.Tech. (Heat Power-Refrigeration \& Air Conditioning) in 2004 from, J.N.T.U. College of Engineering, Anantapur, Andra Pradesh. Presently, she is working as a Scientist at DRDO, Centre for Air Borne Systems, Bangalore. Her areas of interest are electronics cooling, thermal design and analysis. Her contributions to the present work are conceptualization of problem, arriving at the solution methodology, numerical simulation and experimentation. She has published technical articles in Defence Science Journal.

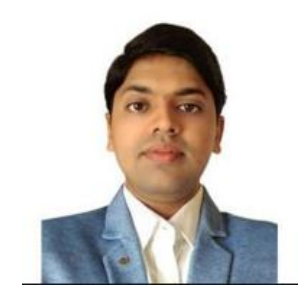


Mr. Yash Krishna Menon received his B.Tech. (Mechanical Engineering) from Mumbai University, in 2014 and M.Tech. (Thermal \& Fluids Engineering) from Amrita University, in 2017. Presently, he is working as a Research Fellow at DRDO-Centre for Air Borne Systems, Bengaluru. His areas of interest are electronics cooling, thermal design and analysis. His contributions to the present work are 3-Dmodelling, MATLAB code development, CFD analyses, Experimental validation and testing. He has published technical articles in Scopus indexed journals.

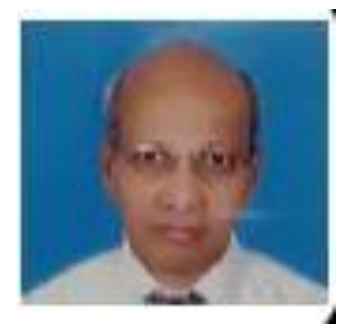

Dr. A C Niranjanappa obtained his Ph. D from Indian Institute of Science, Bangalore. Presently, he is working as Outstanding Scientist at DRDO, Centre for Air Borne Systems, Bangalore. His area of interest involves damage characterization of composite radome. His contribution to the present work is formulating test methodology and analysis of results obtained from the test. He has published technical articles in Scopus indexed journals.

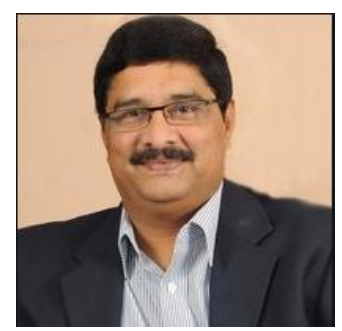

Prof. K. Hema Chandra Reddy has more than 30 years of teaching \& research experience in the field of Mechanical Engineering. He is specialised in the areas of thermal engineering, CFD. He has published 135 technical papers in various national and international journals. He is a professor in Mechanical Engineering at JNTU College of Engineering Ananatapuramu. Currently, he is serving as the Chairman of Andhra Pradesh State Council of Higher Education. His contributions to the present work are about overall guidance to the problem approach. 